OPEN ACCESS

Edited by:

Sanket J. Joshi,

Sultan Qaboos University, Oman

Reviewed by:

Tikam Chand Dakal,

Manipal University Jaipur, India

Aysun Kepekçi,

University of Gaziantep, Turkey

*Correspondence:

Renata Guerra-Sá

rguerra@iceb.ufop.br

Specialty section

This article was submitted to

Microbiotechnology,

a section of the journal

Frontiers in Microbiology

Received: 16 July 2019

Accepted: 31 January 2020

Published: 19 February 2020

Citation:

Ruas FAD and Guerra-Sá $P$ (2020) In silico Prediction of Protein-Protein Interaction Network Induced by Manganese /l

in Meyerozyma guilliermondii.

Front. Microbiol. 11:236.

doi: 10.3389/fmich.2020.00236

\section{In silico Prediction of Protein-Protein Interaction Network Induced by Manganese II in Meyerozyma guilliermondii}

\author{
France Anne Dias Ruas and Renata Guerra-Sá* \\ Laboratório de Bioquímica e Biologia Molecular, Departamento de Ciências Biológicas, Instituto de Ciências Exatas e \\ Biológica (NUPEB), Universidade Federal de Ouro Preto, Ouro Preto, Brazil
}

Recently, there has been an increasing interest in the use of yeast to produce biosorbent materials, because yeast is economical to use, adaptable to a variety of conditions, and amenable to morphological manipulations to yield better raw biomaterials. Previous studies from our laboratory have shown that Meyerozyma guilliermondii, a nonpathogenic haploid yeast (ascomycete), exhibits excellent biosorption capacity for $\mathrm{Mn}^{2+}$, as demonstrated by kinetic analyses. Shotgun/bottom-up analyses of soluble fractions revealed a total of 1257 identified molecules, with 117 proteins expressed in the absence of $\mathrm{Mn}^{2+}$ and 69 expressed only in the presence of $\mathrm{Mn}^{2+}$. In this article, we describe the first in silico prediction and screening of protein-protein interactions (PPIs) in M. guilliermondii using experimental data from shotgun/bottom-up analyses. We also present the categorization of biological processes (BPs), molecular functions (MFs), and metabolic pathways of 71 proteins upregulated in the $M$. guilliermondii proteome in response to stress caused by an excess of $\mathrm{Mn}^{2+}$ ions. Most of the annotated proteins were related to oxidation-reduction processes, metabolism, and response to oxidative stress. We identified seven functional enrichments and 42 metabolic pathways; most proteins belonged to pathways related to metabolic pathways (19 proteins) followed by the biosynthesis of secondary metabolites (10 proteins) in the presence of $\mathrm{Mn}^{2+}$. Using our data, it is possible to infer that defense mechanisms minimize the impact of $\mathrm{Mn}^{2+}$ via the expression of antioxidant proteins, thus allowing adjustment during the defense response. Previous studies have not considered protein interactions in this genus in a manner that permits comparisons. Consequently, the findings of the current study are innovative, highly relevant, and provide a description of interactive complexes and networks that yield insight into the cellular processes of $M$. guilliermondii. Collectively, our data will allow researchers to explore the biotechnological potential of M. guilliermondii in future bioremediation processes.

Keywords: Meyerozyma guilliermondii, manganese, bioremediation, proteome, protein-protein interactions, metabolic pathways 


\section{INTRODUCTION}

Heavy metal pollution represents one of the most serious global environmental problems. Although methods exist to minimize the environmental impact caused by these elements, traditional decontamination methods are known to release toxic products into the environment. The development of new ecological strategies for the efficient treatment of contaminated water is therefore a key target for researchers. Such strategies should be based on biological removal, or bioremediation, which is safer and more economically viable than traditional methods (Azubuike et al., 2016; Bahafid et al., 2017; Amorim et al., 2018).

Manganese (Mn) is a heavy metal that is soluble in water. Under normal circumstances, $\mathrm{Mn}$ is essential for growth, development, and homeostasis; however, serious health problems can arise when excessive amounts of $\mathrm{Mn}$ accumulate in the body (Erikson et al., 2005; Johnson and Hallberg, 2005; Zhao et al., 2010; Kafaei et al., 2017; Kornblith et al., 2018). In the state of Minas Gerais, $\mathrm{Mn}$ is naturally present in the soil and considered a natural constituent of the waters that drain from this region. However, Mn concentrations above the limits set out by environmental resolutions (Conselho Nacional do Meio Ambiente-Conama, 2005, 2011; Instituto Mineiro de Gestão das Águas [IGAM], 2012, 2014) have been found in this region. It is generally thought that this increase in Mn concentration is related to activities in the mining and metallurgical sectors. Indeed, $\mathrm{Mn}$ has been detected in the effluents and drains of almost all Brazilian mining sites (U.S. Department of the Interior and U.S. Geological Survey, 2012; Departamento Nacional de Produção Mineral [DNPM], 2017). A more significant increase in the levels of Mn was detected after the rupture of a dam in the city of Mariana-MG in 2015; dam residues were shown to contain large amounts of manganese. More recently, another dam broke, resulting in the further release of waste into the environment (Departamento Nacional de Produção Mineral [DNPM], 2017).

Traditionally, the removal of $\mathrm{Mn}$ is accomplished by the addition of strong oxidizing agents such as chlorine $\left(\mathrm{Cl}_{2}\right)$, ozone $\left(\mathrm{O}_{3}\right)$, and potassium permanganate $\left(\mathrm{KMnO}_{4}\right)$; however, these agents generate toxic by-products. A potential alternative to these traditional processes is the use of biological technologies, such as bioremediation, that are more economically viable (Patil et al., 2016; Bahafid et al., 2017). The capacity of an organism for bioremediation, along with its tolerance or adaptability, is defined by molecular responses that are unique to each organism. Molecular techniques, such as proteomics and interactomics, allow us to identify and understand the metabolic potential of such organisms (Pandey and Mann, 2000; Mallick and Kuster, 2010). However, little is known about the molecular and biochemical mechanisms responsible for the accumulation and degradation of metals by yeast. In particular, the genetic and molecular basis of tolerance to heavy metals remains poorly understood. Consequently, there is an urgent need to identify the functional genes involved in tolerance and detoxification, and to elucidate the expression of key genes and proteins involved in the accumulation of heavy metals, along with their molecular interactions (Pieper and Reineke, 2000; Wase and Forster, 2003; Dixit et al., 2015; Bahafid et al., 2017).
Interactomics allows researchers to identify all types of molecular interactions, such as protein-protein interactions (PPIs), and examine metabolic networks that are regulated under certain physiological conditions. Analysis of PPIs has been employed in previous research to predict the function of uncharacterized proteins based on the fact that interacting proteins have similar functions (Feng et al., 2014; Cafarelli et al., 2017). Proteins participate in complex networks of biochemical interactions, at both functional and physical levels, between DNA, RNA, other proteins, lipids, and small metabolites. Developing an understanding of cellular mechanisms requires the analysis of interactomic networks using data acquired from proteomics. Oxidative stress caused by excessive levels of metals triggers an increase in gene expression, metabolic factors, and signaling proteins related to the stress response. By specifically analyzing PPIs, it is possible to identify all protein interactions that are upregulated or downregulated in certain environmental scenarios, thus providing clues for the identification of groups of molecules activated during the process of metal resistance; such research could be vital in developing biotechnological processes to facilitate the removal of Mn (Goll and Uetz, 2006; Instituto Mineiro de Gestão das Águas [IGAM], 2012; Feng et al., 2014; López et al., 2016; Patil et al., 2016; Cafarelli et al., 2017; Wang et al., 2018; Ruas et al., 2019).

Meyerozyma guilliermondii is a haploid, osmotolerant, nonpathogenic yeast that is able to utilize various carbon sources for survival and growth. Some strains exhibit physiological characteristics that can be used for the bioremediation of environmental metal contamination (Kaszycki et al., 2004; Butler et al., 2009; Kurtzman et al., 2011; Defosse et al., 2014). In a previous publication, we demonstrated that this strain of yeast may be employed in bioremediation processes to remove $\mathrm{Mn}^{2+}$ ions from water contaminated by mines. We confirmed this biosorptive removal capability using kinetic equations (Amorim et al., 2018), and recently described the first soluble proteome for this genus and this particular species (Ruas et al., 2019).

In the present study, we aimed to create the first PPI map for M. guilliermondii and describe the interaction network of proteins that are upregulated under stress conditions caused by an excess of $\mathrm{Mn}^{2+}$ ions. The present finding provides new insights into the underlying molecular and biochemical mechanisms, particularly the expression of upregulated proteins and the activation of metabolic pathways, under stress conditions caused by the excessive accumulation of Mn. We consider that the present findings related to the molecular mechanisms and kinetics of Mn removal will facilitate the development of new strategies for the application of this $\mathrm{Mn}^{2+}$-resistant yeast in biotechnological processes (Schwikowski et al., 2000; McDermott et al., 2005; Feng et al., 2014).

\section{MATERIALS AND METHODS}

This study involved a dataset that was previously published by our group (Ruas et al., 2019) and deposited in the ProteomeXchange Consortium (Vizcaíno et al., 2014) via the jPOST (Okuda et al., 2017) partner repository; 
this dataset can be accessed using the following dataset identifiers: <PXD010049> and <PXD PXD010050>. This dataset was obtained from M. guilliermondii yeast grown, for 7 days, in Yeast Peptone Dextrose (YPD) medium containing $2 \%(\mathrm{w} / \mathrm{v})$ glucose, $1 \%(\mathrm{w} / \mathrm{v})$ yeast extract, and $2 \%(\mathrm{w} / \mathrm{v})$ peptone $(\mathrm{pH} 7.4)$ and under two different conditions: the absence and presence $0.91 \mathrm{mM}$ of $\mathrm{Mn}^{2+}$ ions.

\section{LC-MS/MS Analysis}

All experiments were conducted in biological duplicates and techniques triplicates. Proteins were extracted, dosed, and subsequently processed separately; $20 \mu \mathrm{g}$ aliquots of protein fractions were separated by electrophoresis short runs in order to concentrate the proteins and eliminate contaminants of low molecular mass such as secondary metabolites. Analysis involved $500 \mathrm{ng}$ of peptides obtained from the enzymatic digestion of biological replicates that were separated by gradient elution using an Acclaim PepMap100 C18 Nano-Trap column (75 $\mu \mathrm{m}$ id $\times 2 \mathrm{~cm}, 3 \mu \mathrm{m}, 100 \AA$, Thermo Scientific) with an Acclaim PepMap100 C18 capillary column (75 $\mu \mathrm{m}$ id $\times 15 \mathrm{~cm}, 2 \mu \mathrm{m}, 100 \AA$, Thermo Scientific). Ultrahigh performance liquid chromatography (UHPLC) separation of previously digested tryptic peptides was performed using the Dionex UltiMate ${ }^{\circledR} 3000$ UHPLC system (Thermo Scientific, Bremen). The spectra of biological duplicates were determined using a Q-Exactive ${ }^{\mathrm{TM}}$ mass spectrometry instrument (Thermo Scientific). The instrument was operated at $1.9 \mathrm{kV}$ in the positive mode with a resolution of 70,000 at $300-1750 \mathrm{~m} / \mathrm{z}$, a maximum injection time of $120 \mathrm{~ms}$ and a target value for automatic gain control (AGC) of 1 and 6 ions. We also used a $2 \mathrm{~m} / z$ window, fragmented by high energy collisional dissociation (HCD) with a normalized collision energy of 28-30 V. MS/MS spectra were obtained at a resolution of 17,500, a maximum injection time of $60 \mathrm{~ms}$, and an AGC target value of 5 and 5 ions. After each MS/MS, we applied a subsequent dynamic deletion of $30 \mathrm{~s}$ (Ruas et al., 2019).

\section{Processing and Storage of Data in a Repository}

Files containing raw data were subsequently searched by quantitative proteomics software package MaxQuant ${ }^{\circledR}$, version 1.5.2.8 (Cox and Mann, 2008). Identified proteins were compared with prediction data in the Meyerozyma guilliermondi UniProt database, which contains 5,520 predicted sequences ${ }^{1}$ (accessed March 2017). In order to validate groups of proteins identified as being upregulated in the presence of an excess of $\mathrm{Mn}^{2+}$ ions in the biological duplicates, we used PEAKS software. We also used MaxQuant ${ }^{\circledR}$ software to compare proteomic similarity and to determine unique proteins, as described previously (Kumar and Mann, 2009).

\section{Protein Interaction Datasets}

Analyses were carried out in silico using a range of bioinformatics tools, as described below. Protein annotation was performed

\footnotetext{
${ }^{1}$ http://www.uniprot.org/uniprot/?query=Meyerozyma+guilliermondii\&sort=
} score using UniProt Knowledgebase (UniProtKB) and proteins identified as "uncharacterized" were subjected to a Basic Local Alignment Search Tool (BLAST) search using the UniProtKB and BLASTp databases and considering a minimum sequence identity of $60 \%$. Analyses of biological process (BP) and molecular function (MF) through Blast2GO Software ${ }^{2}$ via Gene Ontology $\left(\mathrm{GO}^{3}\right)$ and KEGG (Ogata et al., 1999) (Kyoto Encyclopedia of Genes and Genomes ${ }^{4}$ ). The PSORT program was used to predict subcellular protein localization ${ }^{5}$, and biochemical pathways involving differentially expressed proteins were analyzed using TabPath $^{6}$ (Moraes et al., 2017) and KEGG. Interaction analyses were performed using STRING ${ }^{7}$ (version 11.0), as described previously (Feng et al., 2014).

\section{RESULTS}

We successfully identified 1257 proteins in the total proteome of M. guilliermondii. The heatmap shown in Figure 1 demonstrates that proteins were downregulated and upregulated under the two different physiological conditions (the absence and presence of $\mathrm{Mn}^{2+}$ ). Figure 2 and Supplementary Table S1 present for the first time the in silico prediction of the identified proteins, metabolic pathways, and the total proteome enrichment of the genus Meyerozyma sp. Results were obtained from the STRING database.

In total, 71 proteins were upregulated in the presence of an excess of $\mathrm{Mn}^{2+}$ ions. These positively regulated proteins in the presence of $\mathrm{Mn}^{2+}$ ions were classified according to the BPs in which they are involved (Figure 3) and their MFs (Figure 4). Most upregulated proteins relate to BPs associated with the cellular response to stress (32\%), oxidation-reduction processes (11\%), carbohydrate metabolic processes $(5 \%)$, response to oxidative stress (4\%), and phosphorylation (4\%) (Figure 3). The most recurrent MFs in the differential proteome were transferase activity (19\%), coenzyme binding (16\%), oxidoreductase activity (16\%), relative effect on the $\mathrm{CH}-\mathrm{OH}$ group of donors (19\%), NAD as an acceptor for the metal binding (14\%), and ATP binding (12\%) (Figure 4).

The first PPI networks of M. guilliermondii total and differential proteome in silico were performed using the STRING, KEGG, and UniProt database (Figure 2), as well as the first demonstration of stress-rich functional enrichment analysis caused by $\mathrm{Mn}^{2+}$ (Figure 5). Seven functional enrichment analysis of the differentially caused by stress caused by $\mathrm{Mn}^{2+}$ were found: metabolic pathways, glutathione metabolism, biosynthesis of secondary metabolites, biosynthesis of antibiotics, biosynthesis of amino acids, propanoate metabolism, and longevity regulating pathway-multiple species $\left(p=5.29 \times 10^{-6}\right)$ (Figure 5 and Supplementary Table S2). Of these enrichments,

\footnotetext{
${ }^{2}$ https://www.blast2go.com/

${ }^{3}$ http://www.geneontology.org/

${ }^{4}$ https://www.genome.jp/kegg/pathway.html

${ }^{5}$ https://www.psort.org/psortb/

${ }^{6}$ http://200.239.132.160:8686/

${ }^{7}$ https://string-db.org/
} 


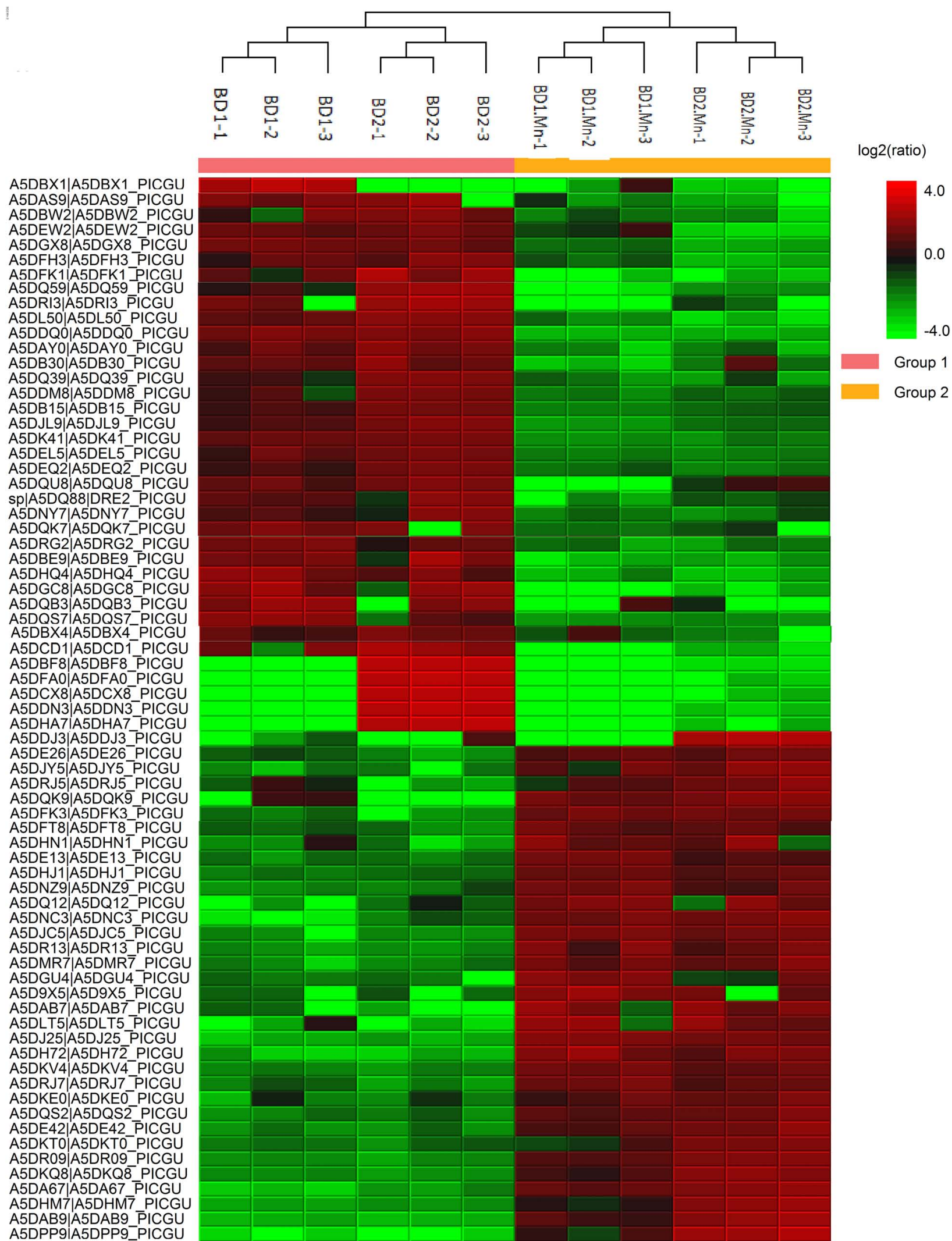

FIGURE 1 | Heatmap representation of peptide quantification for the total proteome of $M$. guilliermondii based on the peak intensity of identified peptides from bottom-up proteomic data in the absence and presence of $\mathrm{Mn}^{2+}$. 


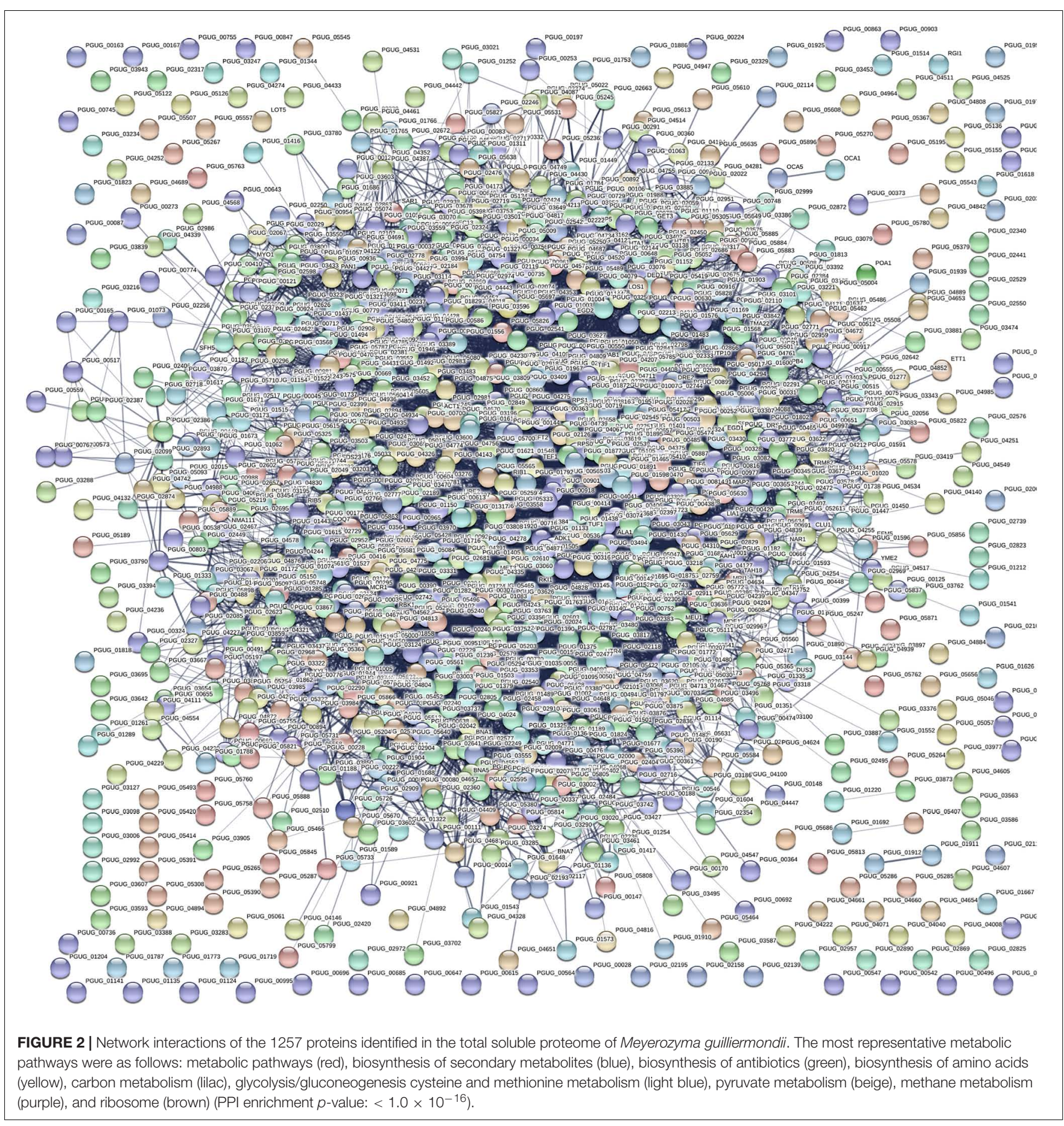

the most representative pathway was metabolic pathways, followed by biosynthesis of secondary metabolites, antibiotics, and amino acids.

More specific analysis of the 71 upregulated proteins showed that they were associated with 42 metabolic pathways. The pathways associated with the largest number of proteins were metabolic pathways (19 proteins) followed by biosynthesis of secondary metabolites (10 proteins), biosynthesis of antibiotics (nine proteins), biosynthesis of amino acids (six proteins), glutathione metabolism (four proteins), and carbon metabolism (four proteins) (Table 2).

\section{DISCUSSION}

Previous studies from our group showed that M. guilliermondii possesses the ability to carry out manganese remediation via an efficient biosorption process. Due to these characteristics, 


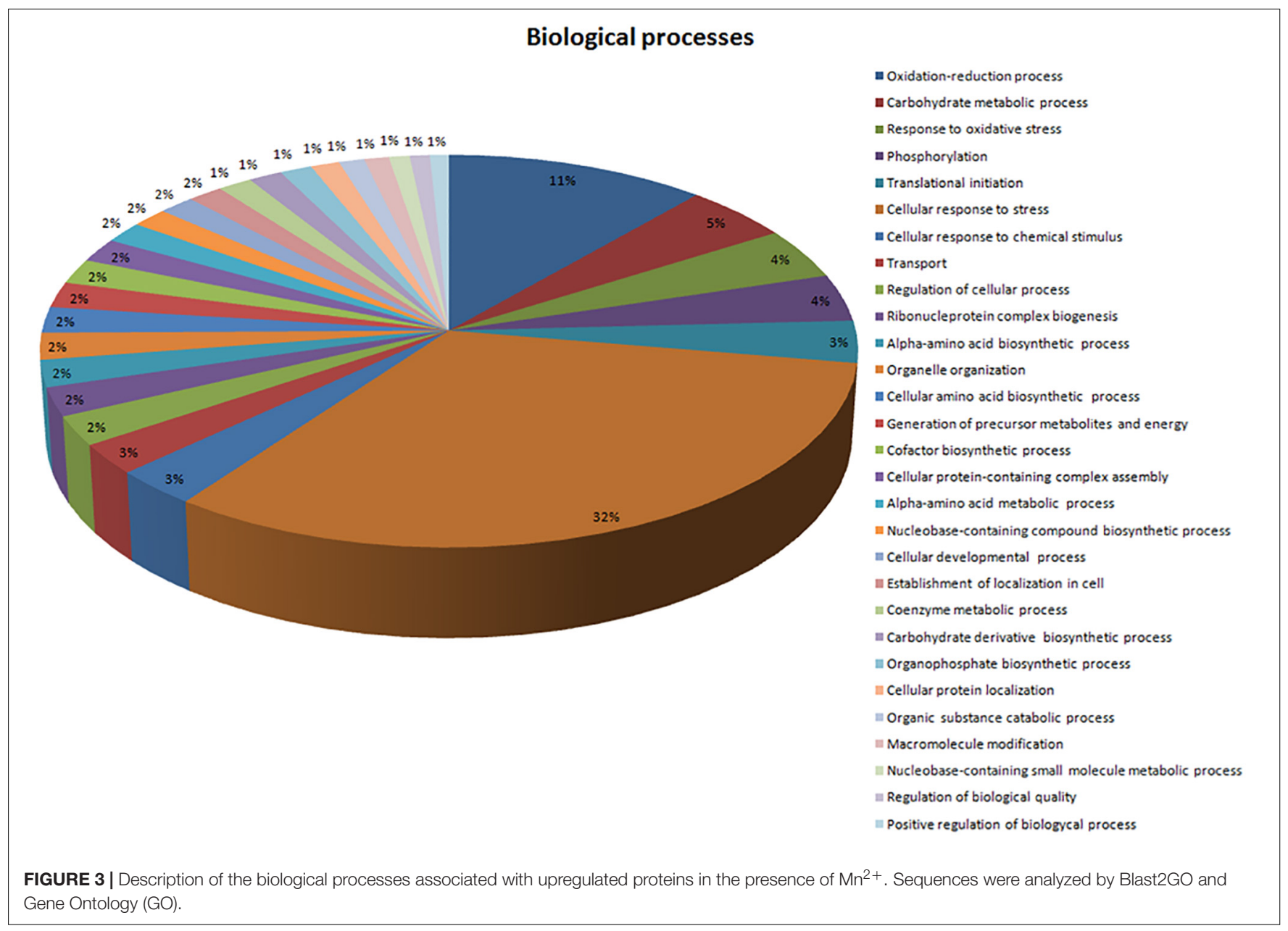

this yeast can be effectively used for bioremediation of metal contamination in contaminated water. Results from the present study provide novel insights into molecular and biochemical mechanisms that allow this species of yeast to tolerate excessive concentrations of $\mathrm{Mn}^{2+}$ (Eccles, 1999; Shakya et al., 2015; Amorim et al., 2018).

In a previous study, we isolated M. guilliermondii and demonstrated that this species of yeast removes $\mathrm{Mn}^{2+}$ ions efficiently. Indeed, our experiments indicated that $100 \%$ of $\mathrm{Mn}^{2+}$ ions were removed from water in only 6 days $(0.91 \mathrm{mM}$ $\left.\mathrm{Mn}^{2+}\right)$; the removal kinetics were also indicative of efficient bioremediation (Amorim et al., 2018). Species that are capable of tolerating excessive concentrations of heavy metals may possess specific biochemical and molecular characteristics such as the expression of specific proteins and metabolic pathways that confer the ability to survive under heavy metal stress. We already know that proteins, their activities, and functions suffer interference from $\mathrm{Mn}^{+2}$, presented in the differential expression of proteins in Figure 1, and that the organism described herein uses such mechanisms to overcome stress conditions to the metal, thus generate a response that allows it to survive under conditions of excess metal. This yeast has mechanisms of gene alteration, differential protein expression, and activation of metabolic pathways that allow to correct and protect cellular and genetic integrity (Stohs and Bagchi, 1995; Kotrba and Ruml, 2000; Chen and Shi, 2002; Ercal et al., 2005; Wysocki and Tamás, 2010; Ruas et al., 2019).

In our previous paper, we reported that the majority of proteins in the proteome of $M$. guilliermondii are involved in BPs related to genetic and metabolic mechanisms (Ruas et al., 2019). The presence of excess $\mathrm{Mn}^{2+}$ ions caused stress to yeast, as expected, since most proteins that were upregulated in the presence of $\mathrm{Mn}^{2+}$ ions are mainly involved in BPs associated with cellular stress response (32\%) (Figure 3). BPs associated with reduction and oxidation processes (11\%) and oxidative stress response (4\%) (Figure 3) also stood out. In general, oxidation-reduction processes act as catalysts for BPs that require electron transfer, such as metabolism and signaling processes that govern gene regulation and expression in certain situations (Prabhulkar et al., 2012). The proteins related to these processes are the majority in the differential proteome (Table $\mathbf{1}$ ).

The key MFs of this expressed proteome are protein binding, transferase activity, and oxidoreductase activity (Figure 4). These results corroborate the number of BPs and demonstrate the capacity of the studied species under stressful conditions 


\section{Molecular function}

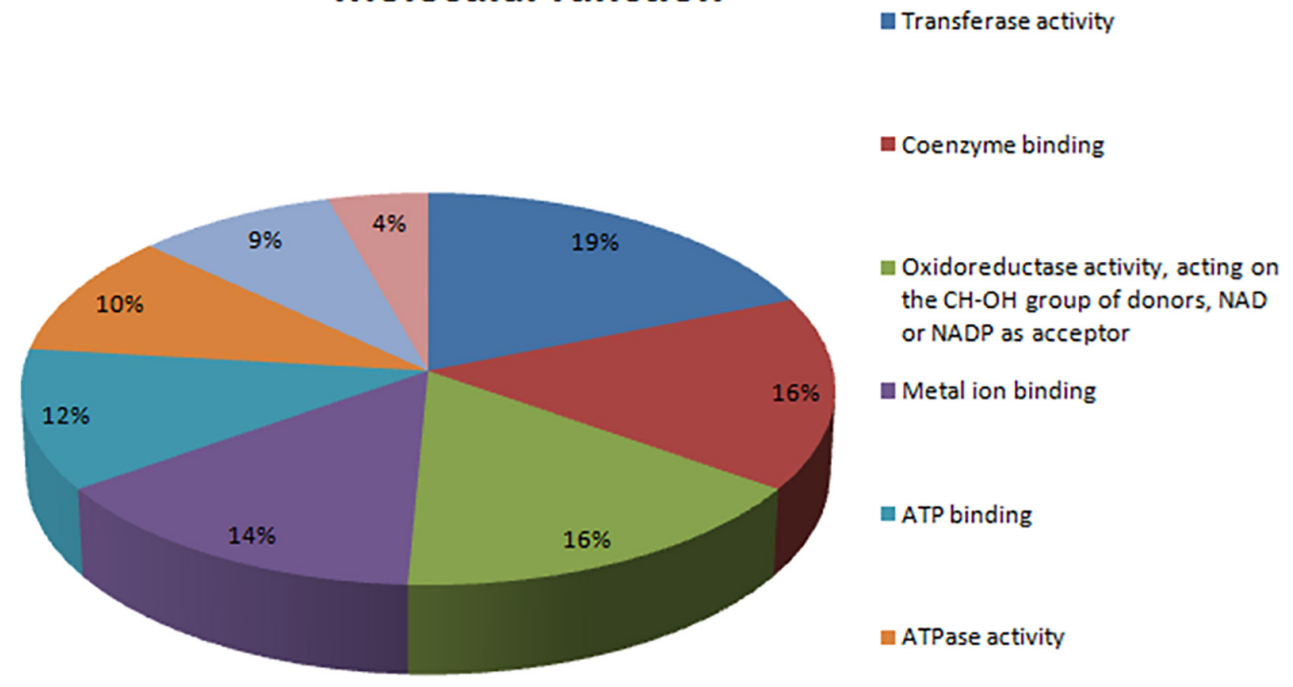

Protein binding

- Translation factor activity, RNA binding

FIGURE 4 | Categorization of the molecular functions of 71 upregulated proteins in the presence of excess Mn, as determined by the bioinformatic platforms Blast2GO and Gene Ontology (GO).

triggered by $\mathrm{Mn}^{2+}$. It has become clear that this species expresses proteins that activate detoxification regulatory mechanisms which allowed it to tolerate considered $\mathrm{Mn}^{2+}$ concentrations (Hohmann and Mager, 2003; Wysocki and Tamás, 2010; Ruas et al., 2019).

Stressful conditions in yeast triggered by the presence of $\mathrm{Mn}^{2+}$ upregulated the expression of 71 proteins. Some of the upregulated proteins were directly related to protein biosynthesis, thus confirming the need for the synthesis of protective proteins in response to overexposure to the tested ions. Others, most of them, are related to oxidation-reduction, metabolism, and oxidative stress response processes. These results confirm that M. guilliermondii has molecular and biochemical mechanisms to overcome $\mathrm{Mn}^{2+}$ toxicity. The effects of metal toxicity on metabolism and homeostasis in M. guilliermondii, particularly in response to Mn exposure, are not known, therefore, the need for this report.

We know that the exposure of cells to excessive concentrations of heavy metals causes an increase in the cellular levels of reactive oxygen species (ROS) that impair and interfere with various cellular components, such as nucleic acids and proteins in yeasts. Heavy metals can cause damage in yeast cells via increased levels of ROS, which lead to the abnormal regulation of redoxsensitive pathways, and through oxidative changes to essential biomolecules (Fridovich, 1998; Shanmuganathan et al., 2004; Ercal et al., 2005; Schrader and Fahimi, 2006; Bonekamp et al., 2009; Pan et al., 2017).
Thus, M. guilliermondii activates these oxidative control mechanisms. Most proteins found in the proteome are related to protein oxidoreductase activity, oxidative stress response, and mitochondrial activity and peroxisomes. This reduction activity is confirmed by the protein interaction network in Figure 5 and the pathway enrichment functional analysis (Table 2). We found upregulated acyl-CoA dehydrogenase (A5DBX1) that catalyzes the early stage of the mitochondrial fatty acid $\beta$-oxidation cycle (Colin and Kimt, 1995). Isocitrate dehydrogenase [NADP] peroxisomal (A5DHQ4), which acts on the krebs cycle by providing NADPH for maintenance of the reduced glutathione and peroxiroxin systems (Table 1 and Supplementary Table S2) (Smolková and Ježek, 2012). The Peroxiredoxin (Prx) (A5DE26) is involved in redox homeostasis and oxidative stress (Bonekamp et al., 2009; Murray et al., 2011; Nelson et al., 2011; Soito et al., 2011) and glutathione S-transferase (A5DBE9, A5DJ25) plays essential role in antioxidant activity (Stohs and Bagchi, 1995).

In studies with Saccharomyces cerevisiae, it was observed that metals and metalloids, such as cadmium $(\mathrm{Cd})$, arsenic III (As III), among other metals, were neutralized. Neutralization triggers a mechanism of glutathione depletion (GSH), usually associated with metal toxicity. GSH depletion influenced the redox environment and impaired the activities of GSH dependent enzymes such as glutathione peroxidases, glutathione S-transferases, and glutaredoxins, affecting many cellular processes (Stohs and Bagchi, 1995). M. guilliermondii 


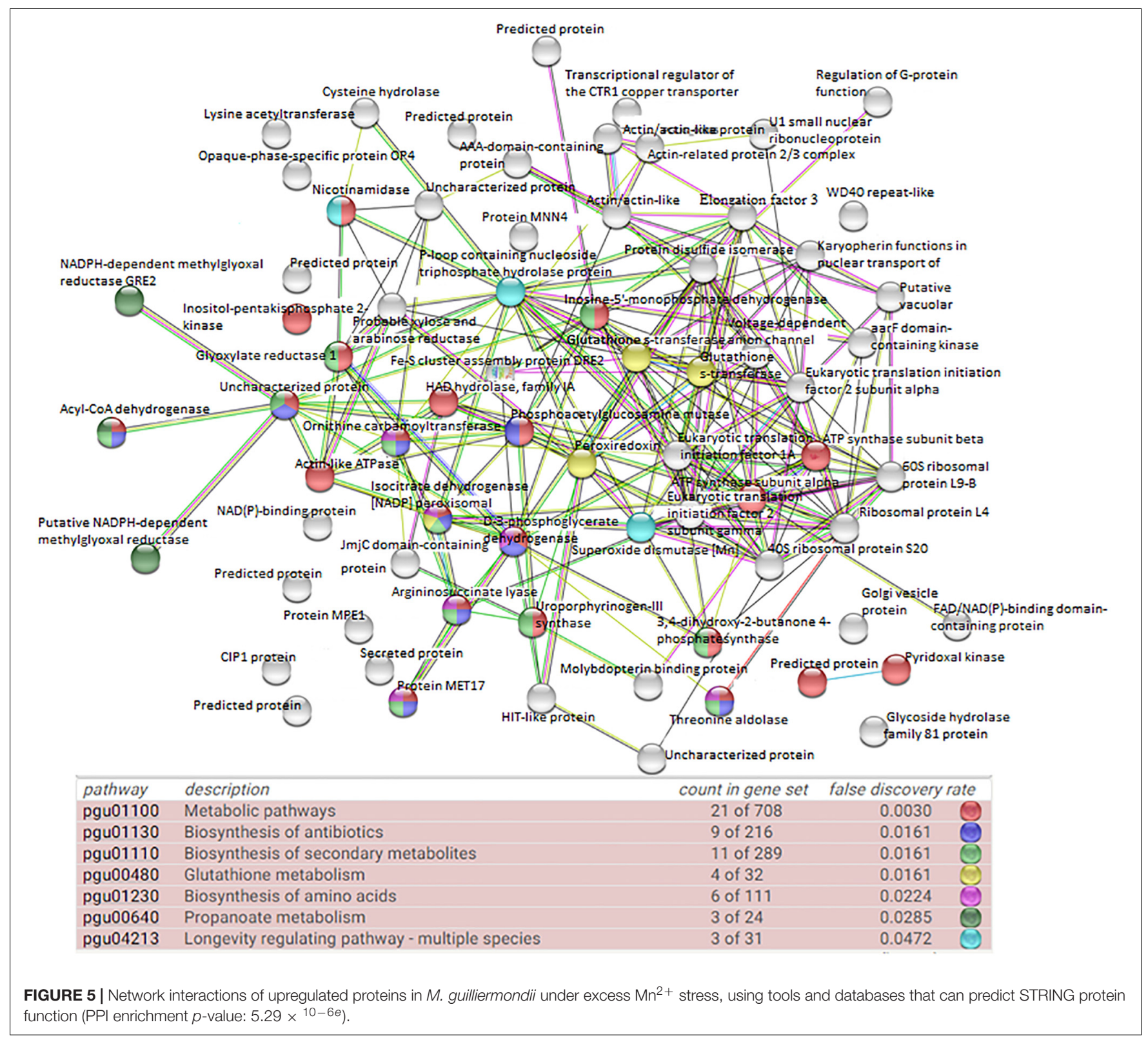

demonstrated that GSH depletion probably does not occur due to the presence of $\mathrm{Mn}^{2+}$. Two glutathione S-transferase (A5DBE9, A5DJ25) have been identified, confirming with data that this yeast has very efficient mechanisms to overcome the stress caused by $\mathrm{Mn}^{2+}$ by protein expression and activation of antioxidant pathways in its cells.

Another protein with important oxidative reduction activity has been expressed as superoxide dismutase $[\mathrm{Mn}]$ mitochondrial (A5DA67), well known as a metalloenzyme that acts against oxidative stress and plays a key role in cellular defense (Ribeiro et al., 2017). We believe that $M$. guilliermondii attenuate damage caused by metals and ROS via the expression of proteins and antioxidant systems, thus allowing ecotoxicological defense response (Fridovich, 1998; Hohmann and Mager, 2003; Hosiner et al., 2014).
We identified using TabPath metabolic pathways of glycolysis/gluconeogenesis (UDP-glucose 4-epimeraseA5DRG2) e via peroxisome (isocitrate dehydrogenase [NADP] peroxisomal-A5DHQ4; superoxide dismutase-A5DA67) (Table 2). Previous research has shown that heavy metal toxicity increases the activity of enzymes such as glucose-6-phosphate dehydrogenase and peroxidases. Heavy metals can also affect plasma membrane lipids by modifying membrane properties linked to permeability, fluidity, the modulation of membranebound ATPase activities, and interfere with proper protein folding (Niki, 2009; Jan et al., 2015).

ATPase activity was identified as one of the MFs that was significantly represented in the proteome of $M$. guilliermondii (10\%) (Figure 4). Damage to cell membrane ATPase activity and increased lipid peroxidation are indication of increased 
TABLE 1 | Differentially expressed proteins in the presence of $\mathrm{Mn}^{2+}$ ions.

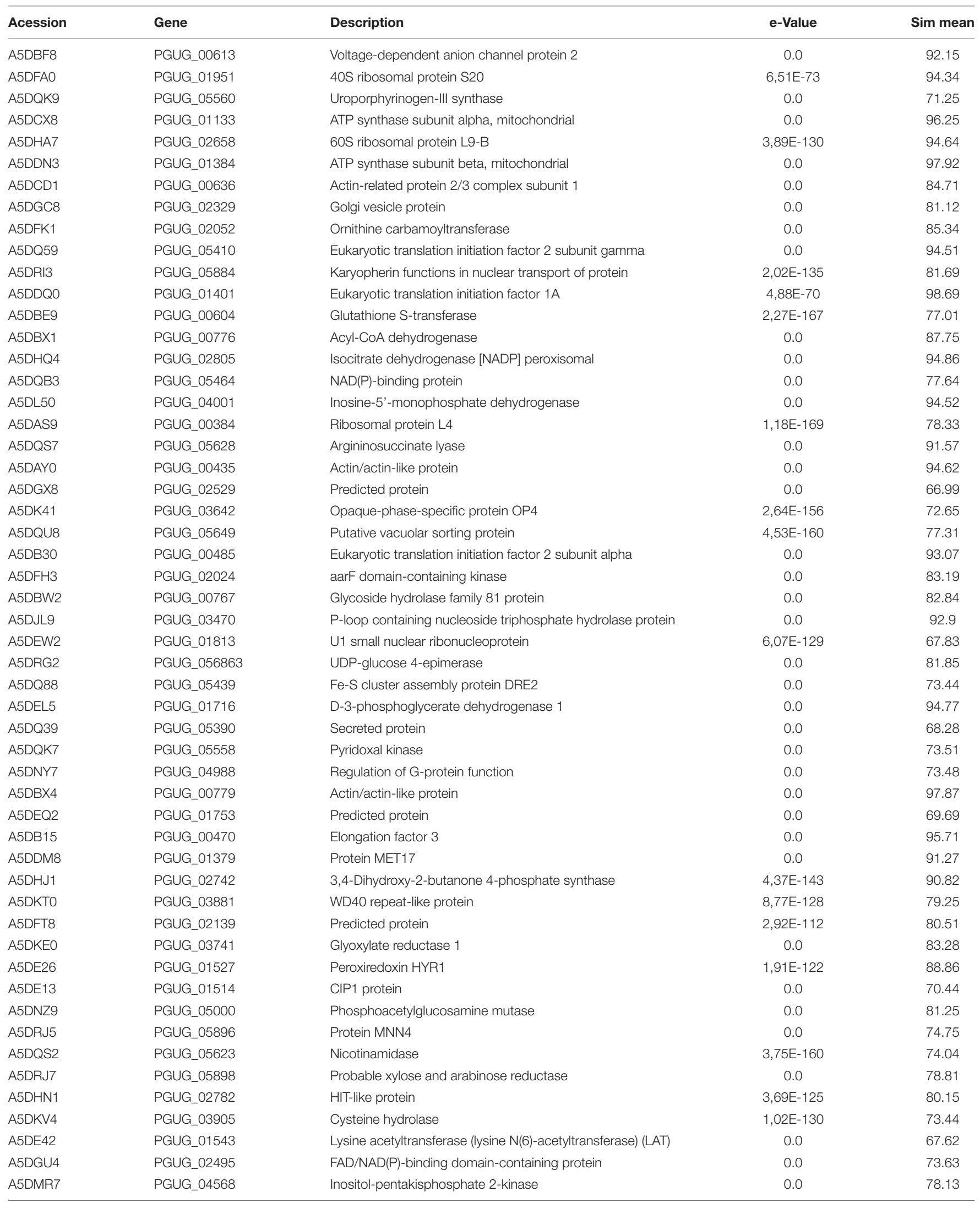


TABLE 1 | Continued

\begin{tabular}{lllr}
\hline Acession & Gene & Description & e-Value \\
\hline A5D9X5 & PGUG_00080 & Threonine aldolase & 0.0 \\
A5DFK3 & PGUG_02054 & NADPH-dependent methylglyoxal reductase GRE2 & 1,76 -123 \\
A5DR09 & PGUG_05710 & SEC14 cytosolic factor & 0.0 \\
A5DKQ8 & PGUG_03859 & Predicted protein & 86.86 \\
A5DR13 & PGUG_05714 & Putative NADPH-dependent methylglyoxal reductase GRP2 & 80.74 \\
A5DQ12 & PGUG_05363 & Actin-like ATPase domain-containing protein & 89.81 \\
A5DJY5 & PGUG_03586 & Predicted protein & 67.0 \\
A5DHM7 & PGUG_02778 & AAA-domain-containing protein & 0.0 \\
A5DJC5 & PGUG_03376 & JmjC domain-containing protein 4 & 2,80 E-110 \\
A5DNC3 & PGUG_04774 & Protein disulfide isomerase & 0.0 \\
A5DDJ3 & PGUG_01344 & - & 0.0 \\
A5DA67 & PGUG_00172 & Superoxide dismutase [Mn], mitochondrial & 82.9 \\
A5DJ25 & PGUG_03276 & Glutathione S-transferase & 65.64 \\
A5DAB9 & PGUG_00224 & Transcriptional regulator of the CTR1 copper transporter & 82.54 \\
A5DLT5 & PGUG_04236 & Predicted protein & 69.22 \\
A5DAB7 & PGUG_00222 & Molybdopterin binding protein & 78.0 \\
A5DH72 & PGUG_02623 & HAD hydrolase, family IA & $4,53 E-148$ \\
A5DPP9 & PGUG_05250 & Protein MPE1 & $2,58 E-170$ \\
\hline
\end{tabular}

oxidative stress caused by metals (Niki, 2009). Adaptive response to lipid peroxidation requires the transcriptional regulation of antioxidant genes, including those encoding enzymes related to glutathione synthesis and metabolism (four proteins: A5DHQ4, A5D26, A5DJ25, A5DBE9) and two glutathione S-transferases (A5DJ25 and A5DBE9) that play a key role in redox homeostasis, cell signaling, and detoxification (Figure 5 and Table 2) (Niki, 2009; Zhang et al., 2013; Jan et al., 2015; Özaslan et al., 2017). The functional enrichment analysis results show the glutathione metabolism pathway as one of the highlights, just as PPI networks show four proteins related to the same functions including two glutathione S-transferase (A5DBE9 and A5DJ25), peroxiredoxin (A5DE26), and peroxisomal isocitrate dehydrogenase [NADP] (A5DHQ4).

Certain metabolic pathways are activated allowing stress to be overcome by detoxification or metal elimination mechanisms. Some induce the precipitation of heavy metals, including metal carbonates, phosphates, and sulfates. Other pathways allow stress to be overcome by mechanisms of detoxification and the elimination of metals. Species that have the ability to adapt or tolerate metals are of very important and could potentially be utilized in important biotechnological processes (Kotrba and Ruml, 2000; Ercal et al., 2005).

Meyerozyma guilliermondii upregulated proteins are involved in 42 metabolic pathways, according to TabPath analysis. Functional enrichment analysis demonstrated seven-way enrichment and that proteins have a network of interactions between proteins that confirm the results of analyzes of biological functions and processes. This pathway relates to several metabolic reactions (catabolism and anabolism) that are necessary for carrying out all processes for body maintenance, including glycolysis, pentose pathway, electron transported chain, and others.
Ten identified proteins belong to biosynthesis of secondary metabolites, which in yeast involves many proteins and protein complexes that allow it to respond to various environmental stimuli such as stress to metals, just as M. guilliermondii was exposed (Fox and Howlett, 2008). Other pathways that have been observed as defense reactions and detoxification mechanisms in yeast due to oxidative damage induced by heavy metals were biosynthesis of amino acids, propanoate, and longevity regulating pathway (Figure 5 and Supplementary Table S2).

Species that possess the ability to remove heavy metals may exhibit adaptive characteristics such as specific metabolic pathways for the remediation of metals. Certain metabolic pathways mediate the precipitation of heavy metals into carbonates, phosphates, and metal sulfates with potential biotechnological applications (Kotrba and Ruml, 2000). In addition, some species can produce metal-binding compounds, such as bio-pigments (flavins, flavonoids, polyhydroxy anthraquinones, and tannin), which contribute to the stress response induced by exposure to metals by acting as the first barrier against a variety of metals. These binders are predominant in metal-binding sites, when dead biomass is used as a biosorbent material (Kotrba and Ruml, 2000; Farooq et al., 2010). Indeed, a recent study involving $M$. guilliermondii reported that dead biomass removed manganese ions more efficiently than live biomass (Amorim et al., 2018), suggesting that metal binding compounds may play a role in this process.

In addition to producing metal binding compounds, biosynthesis of secondary metabolites, amino acids, antibiotics, activation of metabolic pathways also contribute to success in a such stressful situation. Consequently, these factors are of vital importance for the decontamination of metals and thus present meaning for possible biotechnological applications 
TABLE 2 | Metabolic pathways of proteins related to manganese tolerance in differential proteomes.

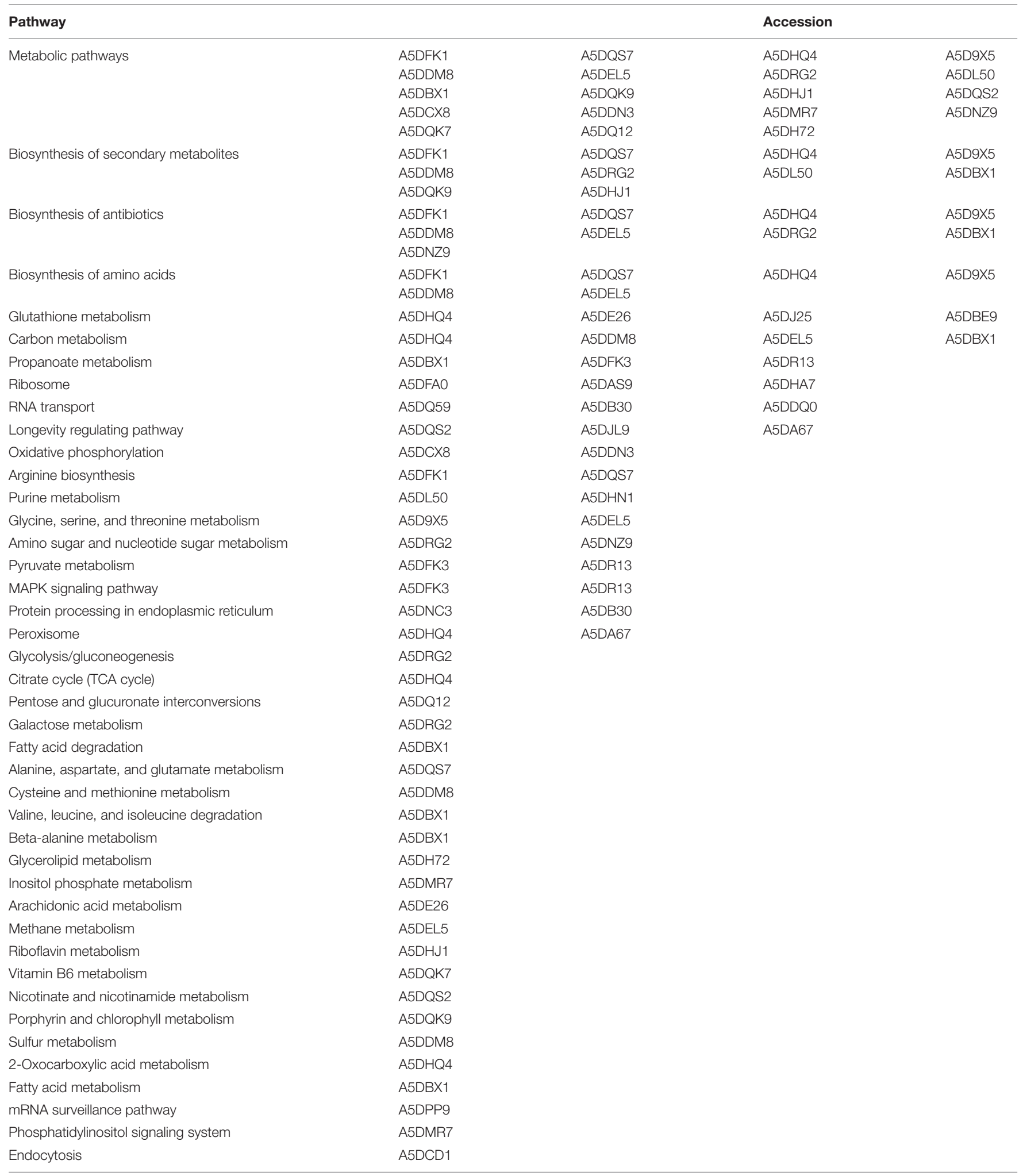

(Holan and Volesky, 1995; Kotrba and Ruml, 2000; Ahemad and Kibret, 2001; Farooq et al., 2010). The possibility of altering the properties of living species used in heavy metal remediation and construction of chimeric organisms that have desirable characteristics using genetic engineering are now under study in many laboratories. 


\section{CONCLUSION}

Heavy metal removal processes by bioremediation represent an economical alternative to physicochemical decontamination methods. In this paper, we describe the molecular interactions of a yeast strain, M. guilliermondii, with proven resistance to $\mathrm{Mn}^{2+}$ ions. Collectively, our findings allow us to identify the molecular interactions associated with proteins that are upregulated in the presence of $\mathrm{Mn}^{2+}$ and describe the metabolic pathways that play a role in the expression of these proteins. The majority of the upregulated proteins were related to oxidoreductase activity. Our findings indicate that M. guilliermondii is able to tolerate excessive $\mathrm{Mn}^{2+}$ concentrations via the expression of antioxidant proteins, thus creating a more effective ecotoxicological defense response. Our data corroborate the findings of previous studies in that this species has significant potential for application in biotechnological processes used to remove $\mathrm{Mn}^{2+}$ contamination from water. The results presented here, in addition to contributing to scientific knowledge about the species, may help to develop future methods for monitoring potentially hazardous and toxic manganese-contaminated areas or waters (rivers, dams). It may further contribute to the establishment of future standardized tests using the species $M$. guilliermondii or even employ as a suitable eukaryotic organism model for bioremediation processes.

\section{DATA AVAILABILITY STATEMENT}

Our mass spectrometry proteomics data have been deposited in the ProteomeXchange Consortium [49] via the

\section{REFERENCES}

Ahemad, M., and Kibret, M. (2001). Recent trends in microbial biosorption of heavy metals: a review. Biotechnol. Bioprocess Eng. 6, 376-385. doi: 10.12966/ bmb.06.02.2013

Amorim, S. S., Ruas, F. A. D., Barboza, N. R., Oliveira, V. G. N., Leão, V. A., and Guerra-Sá, R. (2018). Manganese $\left(\mathrm{Mn}^{2+}\right)$ tolerance and biosorption by Meyerozyma guilliermondii and Meyerozyma caribbica strains. J. Environ. Chem. Eng. 6, 4538-4545. doi: 10.1016/j.jece.2018.06.061

Azubuike, C. C., Chikere, B. C., and Okpokwasili, G. C. (2016). Bioremediation techniques-classification based on site of application: principles, advantages, limitations and prospects. World J. Microbiol. Biotechnol. 32, 1-18. doi: 10.1007/ s11274-016-2137-x

Bahafid, W., Joutey, N. T., Asri, M., Sayel, H., Tirry, N., and Ghachtouli, N. E. (2017). "Yeast biomass: an alternative for bioremediation of heavy metals," in Yeast - Industrial Applications, ed. A. Morata, (Rijeka: IntechOpen), 269-289. doi: 10.5772/intechopen.70559

Bonekamp, N. A., Völkl, A., Fahimi, H. D., and Schrader, M. (2009). Reactive oxygen species and peroxisomes: struggling for balance. Biofactors 35, 346-355. doi: $10.1002 /$ biof.48

Butler, G., Rasmussen, M. D., Lin, M. F., Santos, M. A. S., Sakthikumar, S., Munro, C. A., et al. (2009). Evolution of pathogenicity and sexual reproduction in eight Candida genomes. Nature 459, 657-662. doi: 10.1038/nature 08064

Cafarelli, T., Desbuleux, A., Wang, Y., Choi, S., De Ridder, D., and Vidal, M. (2017). Mapping, modeling, and characterization of protein-protein interactions on a proteomic scale. Curr. Opin. Struct. Biol. 44, 201-210. doi: 10.1016/j.sbi.2017. 05.003
jPOST [50] partner repository with the following dataset identifiers: $<$ PXD010049 $>$ and $<$ PXD010050 $>$.

\section{AUTHOR CONTRIBUTIONS}

FR designed and performed $\mathrm{Mn}^{2+}$ experiments with M. guilliermondii, processed the data, carried out bioinformatic analyses and statistical analysis, deposited the proteomic dataset in public repositories, and wrote and reviewed the manuscript. RG-S designed and supervised the study and reviewed the manuscript. Both authors read and approved the final manuscript.

\section{FUNDING}

This study was sponsored by the Conselho Nacional de Desenvolvimento Científico e Tecnológico (CNPq) CAPES (Coordenacao de Aperfeicoamento de Pessoal de Nivel Superior), Fundação de Amparo à Pesquisa do Estado de Minas Gerais (FAPEMIG), Financiadora de Estudos e Projetos (FINEP), company Vale, and Universidade Federal de Ouro Preto. CAPES granted the stipend for students to conduct the study and UFOP provided the infrastructure.

\section{SUPPLEMENTARY MATERIAL}

The Supplementary Material for this article can be found online at: https://www.frontiersin.org/articles/10.3389/fmicb. 2020.00236/full\#supplementary-material

Chen, F., and Shi, X. (2002). Intracellular signal transduction of cells in response to carcinogenic metals. Crit. Rev. Oncol. Hematol. 42, 105-121. doi: 10.1016/ S1040-8428(01)00211-6

Colin, T., and Kimt, J.-J. P. (1995). Structure and mechanism of action of the acyl-CoA dehydrogenases. FASEB J. 9, 718-725. doi: 10.1096/fasebj.9.9.76 01336

Conselho Nacional do Meio Ambiente-Conama (2005). Resolução No 357, De 17 de março de 2005 - CONAMA. Available at: http://www2.mma.gov.br/port/ conama/legiabre.cfm?codlegi=459 (accessed February 7, 2020).

Conselho Nacional do Meio Ambiente-Conama (2011). Resolução $N^{\circ} 430$, de 13 de maio de 2011- CONAMA. Available at: https://www.mprs.mp.br/media/areas/ gapp/arquivos/atualizacao_intra/dou/res_conama_430.pdf (accessed January 29, 2019).

Cox, J., and Mann, M. (2008). MaxQuant enables high peptide identification rates, individualized p.p.b.-range mass accuracies and proteome-wide protein quantification. Nat. Biotechnol. 26, 1367-1372. doi: 10.1038/nbt. 1511

Defosse, T. A., Melin, C., Obando Montoya, E. J., Lanoue, A., Foureau, E., Glévarec, G., et al. (2014). A new series of vectors for constitutive, inducible or repressible gene expression in Candida guilliermondii. J. Biotechnol. 180, 37-42. doi: 10. 1016/j.jbiotec.2014.03.034

Departamento Nacional de Produção Mineral [DNPM] (2017). Anuário Mineral Brasileiro. Principais substâncias metálicas. Available at: http://www.anm.gov.br/dnpm/publicacoes/serie-estatisticas-e-economiamineral/anuario-mineral/anuario-mineral-brasileiro/amb_metalicos2017 (accessed February 11, 2019).

Dixit, R., Wasiullah Malaviya, D., Pandiyan, K., Singh, U. B., and Sahu, A. (2015). Bioremediation of heavy metals from soil and aquatic environment: 
an overview of principles and criteria of fundamental processes. Sustain 7, 2189-2212. doi: 10.3390/su7022189

Eccles, H. (1999). Treatment of metal-contaminated wastes: why select a biological process? Trends Biotechnol. 17, 462-465. doi: 10.1016/S0167-7799(99)01 381-5

Ercal, N., Gurer-Orhan, H., and Aykin-Burns, N. (2005). Toxic metals and oxidative stress Part I: mechanisms involved in metal induced oxidative damage. Curr. Top. Med. Chem. 1, 529-539. doi: 10.2174/156802601339 4831

Erikson, K. M., Syversen, T., Aschner, J. L., and Aschner, M. (2005). Interactions between excessive manganese exposures and dietary iron-deficiency in neurodegeneration. Environ. Toxicol. Pharmacol. 19, 415-421. doi: 10.1016/j. etap.2004.12.053

Farooq, U., Kozinski, J. A., Khan, M. A., and Athar, M. (2010). Biosorption of heavy metal ions using wheat based biosorbents - a review of the recent literature. Bioresour. Technol. 101, 5043-5053. doi: 10.1016/J.BIORTECH.2010. 02.030

Feng, S., Zhou, L., Xie, K., and Nice, E. C. (2014). Interactomics: toward protein function and regulation. Expert Rev. Proteomics 24, 1-24. doi: 10.1586/ 14789450.2015.1000870

Fox, E. M., and Howlett, B. J. (2008). Secondary metabolism: regulation and role in fungal biology. Curr. Opin. Microbiol. 11, 481-487. doi: 10.1016/j.mib.2008.10. 007

Fridovich, I. (1998). Oxygen toxicity: a radical explanation. J. Exp. Biol. 201, 1203-1209. doi: 10.1242/jeb.037663

Goll, J., and Uetz, P. (2006). The elusive yeast interactome. Genome Biol 7:223. doi: $10.1186 / \mathrm{gb}-2006-7-6-223$

Hohmann, S., and Mager, W. H. (2003). “Opics in current genetics," in Yeast Stress Responses, eds S. Hohmann, and W. H. Mager, (Berlin: Springer Verlag), 389. doi: 10.1017/CBO9781107415324.004

Holan, Z. R., and Volesky, B. (1995). Biosorption of heavy metals: Review. Biotechnol. Prog. 11, 235-250.

Hosiner, D., Gerber, S., Lichtenberg-Fraté, H., Glaser, W., Schüller, C., and Klipp, E. (2014). Impact of acute metal stress in Saccharomyces cerevisiae. PLoS One 9:e83330. doi: 10.1371/journal.pone.0083330

Instituto Mineiro de Gestão das Águas [IGAM] (2012). Monitoramento da Qualidade das Águas Superficiais no Estado de Minas Gerais. Montes Claros: Instituto Mineiro de Gestão das Águas.

Instituto Mineiro de Gestão das Águas [IGAM] (2014). Qualidade das Águas Superficiais de Minas Gerais em 2013. Belo Horizonte: Secretaria. Available at: http://www.igam.mg.gov.br/images/stories/qualidade_aguas/2014/resumoexecutivo-2013.pdf (accessed February 11, 2019).

Jan, A., Azam, M., Siddiqui, K., Ali, A., Choi, I., and Haq, Q. (2015). Heavy metals and human health: mechanistic insight into toxicity and counter defense system of antioxidants. Int. J. Mol. Sci. 16, 29592-29630. doi: 10.3390/ijms161226183

Johnson, D. B., and Hallberg, K. B. (2005). Acid mine drainage remediation options: a review. Sci. Total Environ. 338, 3-14. doi: 10.1016/j.scitotenv.2004 09.002

Kafaei, R., Tahmasbi, R., Ravanipour, M., Vakilabadi, D. R., and Ahmadi, M. (2017). Urinary arsenic, cadmium, manganese, nickel, and vanadium levels of schoolchildren in the vicinity of the industrialised area of Asaluyeh, Iran. Environ. Sci. Pollut. Res. 24, 23498-23507. doi: 10.1007/s11356-0179981-6

Kaszycki, P., Fedorovych, D., Ksheminska, H., Babyak, L., Wójcik, D., and Koloczek, H. (2004). Chromium accumulation by living yeast at various environmental conditions. Microbiol. Res. 159, 11-17. doi: 10.1016/j.micres. 2003.12.002

Kornblith, E., Casey, S. L., Colledge, M. A., and Bowler, R. M. (2018). Environmental exposure to manganese in air: tremor, motor and cognitive symptom profiles. Neurotoxicology 64, 152-158. doi: 10.1016/j.neuro.2017.09. 012

Kotrba, P., and Ruml, T. (2000). Bioremediation of heavy metal pollution exploiting constituents, metabolites and metabolic pathways of livings. A review. Collect. Czechoslov. Chem. Commun. 65, 1205-1247. doi: 10.1135/ $\operatorname{cccc} 20001205$

Kumar, C., and Mann, M. (2009). Bioinformatics analysis of mass spectrometrybased proteomics data sets. FEBS Lett. 583, 1703-1712. doi: 10.1016/j.febslet. 2009.03.035
Kurtzman, C. P., Fell, J. W., and Boekhout, T. (2011). The Yeast, a Taxonomic study, 5th Edn. Burlington, MA: Elsevier.

López, D. A., Gutiérrez, M. A., Lopes, K. P., Prieto, C., Santamaría, R., and Las Rivas, J. D. (2016). APID interactomes: providing proteome-based interactomes with controlled quality for multiple species and derived networks. Nucleic Acids Res. 44, W529-W535. doi: 10.1093/nar/gkw363

Mallick, P., and Kuster, B. (2010). Proteomics: a pragmatic perspective. Nat. Biotechnol. 28, 695-709. doi: 10.1038/nbt.1658

McDermott, J., Bumgarner, R., and Samudrala, R. (2005). Functional annotation from predicted protein interaction networks. Bioinformatics 21, 3217-3226. doi: 10.1093/bioinformatics/bti514

Moraes, L. Â. G., Felestrino, É. B., Assis, R. A. B., Matos, D., Lima, J. C., Lima, L. A., et al. (2017). TabPath: interactive tables for metabolic pathway analysis. Bioinformatics 34, 1040-1042. doi: 10.1093/bioinformatics/btx714

Murray, D. B., Haynes, K., and Tomita, M. (2011). Redox regulation in respiring Saccharomyces cerevisiae. Biochim. Biophys. Acta Gen. Subj. 1810, 945-958. doi: 10.1016/j.bbagen.2011.04.005

Nelson, K. J., Knutson, S. T., Soito, L., Klomsiri, C., Leslie, B., and Fetrow, J. S. (2011). Analysis of the peroxiredoxin family: using active site structure and sequence information for global classification and residue analysis. Proteins 79, 947-964. doi: 10.1002/prot.22936

Niki, E. (2009). Lipid peroxidation: physiological levels and dual biological effects. Free Radic. Biol. Med. 47, 469-484. doi: 10.1016/j.freeradbiomed.2009.05.032

Ogata, H., Goto, S., Sato, K., Fujibuchi, W., Bono, H., and Kanehisa, M. (1999). KEGG: kyoto encyclopedia of genes and genomes. Nucleic Acids Res. 27, 29-34. doi: 10.1093/nar/27.1.29

Okuda, S., Watanabe, Y., Moriya, Y., Kawano, S., Yamamoto, T., Matsumoto, M., et al. (2017). JPOSTrepo: an international standard data repository for proteomes. Nucleic Acids Res. 45, D1107-D1111. doi: 10.1093/nar/gkw1080

Özaslan, M. S., Demir, Y., Küfrevioğlu, I., and Çiftci, M. (2017). Some metals inhibit the glutathione S-transferase from Van Lake fish gills. J. Biochem. Mol. Toxicol 31:e21967. doi: 10.1002/jbt.21967

Pan, J., Huang, X., Li, Y., Li, M., Yao, N., Zhou, Z., et al. (2017). Zinc protects against cadmium-induced toxicity by regulating oxidative stress, ions homeostasis and protein synthesis. Chemosphere 188, 265-273. doi: 10.1016/j.chemosphere. 2017.08.106

Pandey, A., and Mann, M. (2000). Proteomics to study genes and genomes. Nature 405, 837-846. doi: 10.1038/35015709

Patil, D. S., Chavan, S. M., and Oubagaranadin, J. U. K. (2016). A review of technologies for manganese removal from wastewaters. J. Environ. Chem. Eng. 4, 468-487. doi: 10.1016/j.jece.2015.11.028

Pieper, D. H., and Reineke, W. (2000). Engineering bacteria for bioremediation of persistent organochlorine. Curr. Opin. Biotechnol. 149, 262-270. doi: 10.1016/j. biortech.2013.09.084

Prabhulkar, S., Tian, H., Wang, X., Zhu, J.-J., and Li, C.-Z. (2012). Engineered proteins: redox properties and their applications. Antioxid. Redox Signal. 17, 1796-1822. doi: 10.1089/ars.2011.4001

Ribeiro, T. P., Fonseca, F. L., de Carvalho, M. D. C., Godinho, R. M., de Almeida, F. P., Saint'Pierre, T. D., et al. (2017). Metal-based superoxide dismutase and catalase mimics reduce oxidative stress biomarkers and extend life span of Saccharomyces cerevisiae. Biochem. J. 474, 301-315. doi: 10.1042/BCJ201 60480

Ruas, F. A. D., Barboza, N. R., Castro-Borges, W., and Guerra-Sá, R. (2019). Manganese alters expression of proteins involved in the oxidative stress of Meyerozyma guilliermondii. J. Proteomics 196, 173-188. doi: 10.1016/j.jprot. 2018.11.001

Schrader, M., and Fahimi, H. D. (2006). Peroxisomes and oxidative stress. Biochim. Biophys. Acta Mol. Cell Res. 1763, 1755-1766. doi: 10.1016/j.bbamcr.2006.09. 006

Schwikowski, B., Uetz, P., and Fields, S. (2000). A network of proteinprotein interactions in yeast. Nat. Biotechnol. 18, 1257-1261. doi: 10.1038/ 82360

Shakya, M., Sharma, P., Meryem, S. S., Mahmood, Q., and Kumar, A. (2015). Heavy metal removal from industrial wastewater using fungi: uptake mechanism and biochemical aspects. J. Environ. Eng. 142, C6015001. doi: 10.1061/(asce)ee. 1943-7870.0000983

Shanmuganathan, A., Avery, S. V., Willetts, S. A., and Houghton, J. E. (2004). Copper-induced oxidative stress in Saccharomyces cerevisiae targets enzymes of 
the glycolytic pathway. FEBS Lett. 556, 253-259. doi: 10.1016/S0014-5793(03) 01428-5

Smolková, K., and Ježek, P. (2012). The role of mitochondrial NADPH-dependent isocitrate dehydrogenase in cancer cells. Int. J. Cell Biol. 2012, 1-12. doi: 10. $1155 / 2012 / 273947$

Soito, L., Williamson, C., Knutson, S. T., Fetrow, J. S., Poole, L. B., and Nelson, K. J. (2011). PREX: PeroxiRedoxin classification indEX, a database of subfamily assignments across the diverse peroxiredoxin family. Nucleic Acids Res. 39, 332-337. doi: 10.1093/nar/gkq1060

Stohs, S. J., and Bagchi, D. (1995). Oxidative mechanisms in the toxicity of metal ions. Free Radic. Biol. Med. 18, 321-336. doi: 10.1016/0891-5849(94)00159-H

U.S. Department of the Interior, and U.S. Geological Survey, (2012). Mineral commodity summaries. Reston, VA: U.S. Geological Survey.

Vizcaíno, J. A., Deutsch, E. W., Wang, R., Csordas, A., Reisinger, F., and Ríos, D. (2014). ProteomeXchange provides globally co-ordinated proteomics data submission and dissemination. Nat. Biotechnol 32, 223-226. doi: 10.1038/nbt. 2839

Wang, L., Eftekhari, P., Schachner, D., Ignatova, I. D., Palme, V., Schilcher, N., et al. (2018). Novel interactomics approach identifies ABCAl as direct target of evodiamine, which increases macrophage cholesterol efflux. Sci. Rep. 8, 1-10. doi: $10.1038 / s 41598-018-29281-1$

Wase, J., and Forster, C. (2003). Biosorbents for Metal Ions. Available at: http://old2017.metal.ntua.gr/uploads/2746/121/1997_Biosorption_of_ lanthanides_actinides_and_related_materials.pdf (accessed January 28, 2019).

Wysocki, R., and Tamás, M. J. (2010). How Saccharomyces cerevisiae copes with toxic metals and metalloids. FEMS Microbiol. Rev. 34, 925-951. doi: 10.1111/j. 1574-6976.2010.00217.x

Zhang, W., Yin, K., Li, B., and Chen, L. (2013). A glutathione S-transferase from Proteus mirabilis involved in heavy metal resistance and its potential application in removal of $\mathrm{Hg}^{2+}$. J. Hazard. Mater. 261, 646-652. doi: 10.1016/j.jhazmat. 2013.08.023

Zhao, Y., Zhu, G., and Cheng, Z. (2010). Thermal analysis and kinetic modeling of manganese oxide ore reduction using biomass straw as reductant. Hydrometallurgy 105, 96-102. doi: 10.1016/j.hydromet.2010.08.004

Conflict of Interest: The authors declare that the research was conducted in the absence of any commercial or financial relationships that could be construed as a potential conflict of interest.

Copyright (c) 2020 Ruas and Guerra-Sá. This is an open-access article distributed under the terms of the Creative Commons Attribution License (CC BY). The use, distribution or reproduction in other forums is permitted, provided the original author(s) and the copyright owner(s) are credited and that the original publication in this journal is cited, in accordance with accepted academic practice. No use, distribution or reproduction is permitted which does not comply with these terms. 